\title{
HUBUNGAN PENGETAHUAN DAN SIKAP IBU TENTANG PENCEGAHAN CEDERA DENGAN KEJADIAN CEDERA PADA ANAK TODDLER 1-3 TAHUN DI WILAYAH PUSKESMAS TAMBARUNTUNG
}

\author{
Rusdiana Rusdiana \\ Program Studi Diploma Tiga Keperawatan Stikes Intan Martapura, Indonesia \\ Email : rusdianaardiana@gmail.com
}

\begin{abstract}
ABSTRAK
Pencegahan cedera meminimalkan terjadinya kecelakaan pada anak akibat pengawasan yang kurang dari ibu. Penelitian dilakukan untuk mengetahui upaya pencegahan cedera pada anak usia toddler ditinjau berbagai aspek seperti pengetahuan dan sikap ibu terhadap pencegahan cedera. Penelitian menggunakan desain analitik korelasional menggunakan pendekatan cross sectional, serta pengambilan sampel dengan teknik random sampling. Sampel 13 posyandu diambil 6 posyandu dengan sample 35 ibu yang memiliki anak usia toddler 1-3 tahun diwilayah Puskesmas Tambaruntung. Prosedur yang digunakan untuk mengambil data penelitian yaitu dengan melakukan penyebaran instrument kuesioner. Hasil penelitian menunjukan mayoritas responden berpengetahuan baik dalam pencegahan cedera yaitu sebanyak 16 responden $(45,7 \%)$. Hasil penelitian yang didapatkan perlu untuk terus dipertahankan oleh petugas kesehatan dan lebih meningkatkan pelayanan kesehatan memberikan penyuluhan kesehatan tentang pencegahan cedera pada anak usia toddler. Upaya peningkatan pengetahuan perlu dilakukan oleh ibu agar mampu melindungi, menjamin kesehatan, keamanan serta keselamatan anak ketika beraktifitas untuk meminimalisir bahaya cedera.
\end{abstract}

Kata kunci : pengetahun, sikap, pencegahan cedera, toddler

\section{ABSTRACT}

Injury prevention minimizes the occurrence of accidents in children due to lack of supervision from the mother. The study was conducted to determine the efforts to prevent injuries in toddlers in terms of various aspects such as knowledge and attitudes of mothers towards injury prevention. The study used a correlational analytic design using a cross sectional approach, as well as sampling with random sampling techniques. A sample of 13 posyandu was taken from 6 posyandu with a sample of 35 mothers who have toddlers aged 1-3 years in the Tambaruntung Health Center area. The procedure used to collect research data is by distributing the questionnaire instrument. The results showed that the majority of respondents had good knowledge of injury prevention as many as 16 respondents (45.7\%). The results of the research obtained need to be maintained by health workers and further improve health services by providing health education about injury prevention in toddler age children. Efforts to increase knowledge need to be carried out by mothers to be able to protect, ensure the health, safety and safety of children when doing activities to minimize the danger of injury.

Keywords: knowledge, attitude, injury prevention, toddler

Cite this as : $\quad$ Rusdiana, R. (2021). Hubungan Pengetahuan dan Sikap Ibu tentang Pencegahan Cedera dengan Kejadian Cedera pada Anak Toddler 1-3 Tahun di Wilayah Puskesmas Tambaruntung. Jurnal Ilmu Kesehatan Insan Sehat, 9(1), 5-9.

\section{PENDAHULUAN}

Waktu kanak-kanak khususnya masa todler merupakan puncak keingintahuan anak dengan hal baru termasuk lingkungan yang ada disekitarnya. Pada masa ini, anak sangat aktif menggunakan seluruh 
panca indra tanpa mengerti akan bahaya yang mungkin terjadi, sehingga anak pada usia todler rentan terjadi bahaya yang dapat berakibat kecelakaan yang bersifat menetap dan harus ditanggung oleh anak sepanjang usianya (Sutini,2018). Kejadian kecelakaan seringkali dialami oleh anak usia toddler terkadang bisa mengakibatkan terluka hingga menyebabkan kematian jika kecelakaan yang dialami terlalu parah. Cedera atau bahaya fisik yang sering terjadi pada usia toddler sangat banyak yaitu terjatuh, terpeleset, aspirasi makanan, keracunan, luka bakar, tenggelam, serta kecelakaan akibat kendaraan bermotor (Nisa, 2017). Hal ini perlu menjadi perhatian orangtua, terutama ibu untuk menghindarkan anak dari risiko terkena cedera fisik.

Aspek pengetahuan berkaitan dengan pertumbuhan dan perkembangan toddler perlu ditingkatkan sebagai upaya pencegahan cedera pada anak usia toddler. Selain itu, pemahaman tentang pentingnya pencegahan cedera juga dapat ditekankan kepada ibu agar mampu merawat dan menjaga dengan baik anaknya pada usia tersebut. Sikap ibu yang sering membiarkan anaknya bermain sendirian tanpa pengawasan sangat berisiko terhadap keamanan dan keselamatan anak. Pengawasan penting dilakukan ibu, karena anak belum memahami risiko bahaya yang mungkin terjadi dari aktifitas yang dilakukannya (Potter \& Perry,2009).

Ibu dengan pengetahuan yang baik mengenai pencegahan cedera pada anak usia toddler tentunya mampu menilai serta memiliki sikap dan perilaku yang baik terhadap upaya mencegah terjadinya bahaya fisik yang mengancam anak (Notoatmodjo,2007).

Cedera adalah salah satu penyebab dan mortalitas pediatri yang perlu dicegah (Marcdante \& Kliegman, 2013). Data seluruh dunia dari World Health Organization (WHO) dalam penelitian Indarwati dan Ratna Dewi, didapatkan data sebanyak 875.000 anak toddler meninggal per tahunnya akibat cedera, baik yang disengaja maupun yang tidak disengaja. Tingginya angka kematian, terjadi di Negara-negara yang berkembang. Indonesia menjadi salah satu Negara yang cukup tinggi mengalami kejadian cedera, diantaranya akibat jatuh sebanyak $79,4 \%$, mengalami kecelakaan sepeda motor $6,5 \%$, kecelakaan transportasi darat lainnya $5,4 \%$, terluka karena benda tumpul dan tajam sebanyak $4,2 \%$, kejatuhan 2,3\%, terbakar $1,5 \%$ dan akibat gigitan hewan 0,3\% (Kementerian Kesehatan RI, 2013).

Berdasarkan Data dari Riskesdas Tahun 2015, Prevalensi cedera pada anak berdasarkan tingkat kabupaten di Provinsi Kalimantan Selatan sebesar 12,0\% (rentang: 1,9-23,8\%), didapatkan prevalensi tertinggi terjadi dikota Banjarmasin, Banjar, dan Hulu Sungai Selatan. Prevalensi penyebab terjadinya cedera pada anak yang tertinggi adalah disebabkan jatuh $(61,2 \%)$, anak terluka benda tajam/tumpul $(23,6 \%)$, 6 dan anak kecelakaan transportasi di darat $(17,9 \%)$. Prevalensi cedera pada anak dibagian tubuh pergelangan tangan dan tangan $(31,9 \%)$, di lutut dan tungkai bawah $(31,4 \%)$, dan di bagian tumit serta kaki $(25,4 \%)$.

Pemberian edukasi mengenai pecegahan cedera bagi anak usia toddler dapat juga diberikan oleh perawat kepada Ibu anak tersebut. Peran perawat anak sebagai advokat anak dan keluarga, perawat melindungi dan meningkatkan perhatian terhadap anak-anak dan keluarga mereka dengan mengetahui kebutuhan dan sumber daya mereka, memberi mereka informasi tentang hak dan pilihan mereka, serta membantu mereka untuk mengambil keputusan yang terbaik, terutama meningkatkan perhatian dalam bidang pencegahan cedera. Peran perawat sebagai pendidik, perawat harus mampu memberikan informasi kesehatan dan memfasilitasi konseling yang diperuntukan untuk anak-anak serta keluarga mengenai berbagai aspek kesehatan dan kesakitan. Perawat juga memberikan informasi khusus berkaitan pencegahan cedera pada anak usia toddler untuk membekali ibu agar mampu merawat dan menjaga anaknya dengan baik (Hidayat, 2009)

Berdasarkan latar belakang dan data-data yang didapatkan, penulis tertarik untuk mengangkat masalah pencegahan cedera pada anak toddler untuk melihat keterkaitan hubungan antara pengetahuan dan sikap ibu dalam pencegahan cedera pada anak usia Toddler.

\section{METODE}

Penelitian ini menggunakan desain deskriptif analitik dengan pendekatan cross sectional yang memiliki tujuan untuk mengidentifikasi serta mengetahui ada atau tidak hubungan antara pengetahuan dan sikap ibu dengan kejadian cedera pada anak usia toddler (Notoadmojo, 2014). Populasi dalam penelitian ini adalah ibu yang memiliki anak berusia toddler (1-3 tahun) yang datang ke 6 posyandu Puskesmas Tambaruntung Kabupaten Tapin yang didapatkan sebanyak 35 orang.

Prosedur pengambilan sampel dilakukan dengan memberikan kuesioner yang telah di validasi sebelumnya. Pengambilan sampel penelitian menggunakan teknik accidental sampling. Teknik penentuan sampel berdasarkan kebetulan, yaitu secara insidensial bertemu dengan peneliti saat pengambilan sampel berlangsung dan memenuhi kriteria yang ditetapkan sesuai penelitian ini. 
HASIL

Tabel 1 : Distribusi Frekuensi Karakteristik

Responden Berdasarkan Usia di Wilayah Puskesmas Tambaruntung Kabupaten Tapin

Tahun 2020

\begin{tabular}{cccc}
\hline No. & Umur & N & \% \\
\hline 1 & $17-25$ & 10 & 28.6 \\
\hline 2 & $26-35$ & 14 & 40.0 \\
\hline 3 & $36-45$ & 9 & 25.7 \\
\hline 4 & $46-55$ & 2 & 5.7 \\
\hline & Total & $\mathbf{3 5}$ & $\mathbf{1 0 0}$ \\
\hline
\end{tabular}

(Sumber : Data Primer 2020)

Berdasarkan tabel 1 menunjukan bahwa golongan usia responden di Wilayah Puskesmas Tambaruntung Kabupaten Tapin yang terbanyak adalah 36-45 tahun yaitu 14 orang (40\%).

Tabel 2: Distribusi Frekuensi Karakteristik Responden Berdasarkan Pendidikan di Wilayah Puskesmas Tambaruntung Kabupaten Tapin Tahun 2020

\begin{tabular}{cccc}
\hline No. & Pendidikan & N & \% \\
\hline 1. & Tidak Sekolah & 1 & 2.9 \\
\hline 2. & SMP & 25 & 71.4 \\
\hline 3. & SMA & 4 & 27.0 \\
\hline 4. & Perguruan Tinggi & 5 & 14,3 \\
\hline \multicolumn{2}{r}{ Total } & $\mathbf{3 5}$ & $\mathbf{1 0 0}$ \\
\hline
\end{tabular}

(Sumber : Data Primer 2020)

Berdasarkan Tabel 2 menunjukan bahwa golongan pendidikan di Wilayah Puskesmas Tambaruntung Kabupaten Tapin yang Terbanyak adalah sekolah menengah pertama yaitu 25 orang $(71.4 \%)$

Tabel 3:Distribusi Frekuensi Karakteristik Berdasarkan Pekerjaan Responden di Wilayah Puskesmas Tambaruntung Kabupaten Tapin Tahun 2020

\begin{tabular}{cccc}
\hline No. & Pekerjaan & N & \% \\
\hline 1 & IRT & 18 & 51.4 \\
\hline 2 & Swasta & 16 & 45.7 \\
\hline 3 & PNS & 1 & 2.9 \\
\hline & Total & $\mathbf{3 5}$ & $\mathbf{1 0 0}$ \\
\hline
\end{tabular}

(Sumber : Data Primer 2020)

Berdasarkan tabel 3 diatas menunjukan golongan pekerjaan di Wilayah Puskesmas Kabupaten Tapin yang terbanyak adalah Tidak Berkerja yaitu 18 orang $(51,4 \%)$.

Tabel 4: Distribusi Frekuensi Karakteristik Responden Berdasarkan Pengetahuan di Wilayah Puskesmas Tambaruntung Kabupaten Tapin Tahun 2020.

http://jurnalstikesintanmartapura.com/index.php/jikis

\begin{tabular}{cccc}
\hline No & Pengetahuan & N & \% \\
\hline 1. & Baik & 16 & 45.7 \\
\hline 2. & Cukup & 13 & 37.1 \\
\hline 3. & Kurang & 6 & 17.1 \\
\hline & Total & $\mathbf{3 5}$ & $\mathbf{1 0 0}$ \\
\hline
\end{tabular}

Berdasarkan tabel 4 diatas menunjukan bahwa golongan Pengetahuan di Wilayah Puskesmas Tambaruntung Kabupaten Tapin dari 35 responden yang menjadi sampel yaitu menerapkan Pengetahuan Baik 16 orang (45.7\%), Pengetahuan Cukup 13 orang $(37,1 \%)$, Pengetahuan Kurang 6 orang $(17,1 \%)$.

Tabel 5: Distribusi Frekuensi Responden Berdasarkan Sikap Pencegahan Cedera di Wilayah Puskesmas Tambaruntung Kabupaten Tapin Tahun 2020.

\begin{tabular}{cccc}
\hline No & Sikap & N & \% \\
\hline 1. & Negatif & 15 & 42.9 \\
\hline 2. & Positif & 20 & 57.1 \\
\hline & Total & $\mathbf{3 5}$ & $\mathbf{1 0 0}$
\end{tabular}

(Sumber : Data Primer 2020)

Berdasarkan tabel 5 menunjukan bahwa Sikap responden di Wilayah Puskesmas Tambaruntung dari 35 responden yang menjadi sampel yaitu 20 orang (57.1\%) memiliki Sikap Positif , 15 orang (42.9\%) memiliki Sikap Negatif.

Tabel 6: Distribusi frekuensi berdasarkan Tabulasi Silang Pengetahuan Dan Sikap ibu Tentang Pencegahan Cedera Dengan Kejadian Cedera di Wilayah Puskesmas Tambaruntung Kabupaten Tapin Tahun 2020.

\begin{tabular}{ccccccc}
\hline \multirow{2}{*}{ Pengetahuan } & \multicolumn{7}{c}{ Sikap } \\
\cline { 2 - 7 } & \multicolumn{2}{c}{ Negatif } & \multicolumn{2}{c}{ Positif } & \multicolumn{2}{c}{ Total } \\
\cline { 2 - 7 } & $\mathrm{N}$ & $\%$ & $\mathrm{~N}$ & $\%$ & $\mathrm{~N}$ & $\%$ \\
\hline Baik & 4 & 11 & 12 & 34 & 16 & 46 \\
\hline Cukup & 5 & 14 & 8 & 23 & 13 & 37 \\
\hline Kurang & 6 & 17 & 0 & 0 & 6 & 17 \\
\hline Total & $\mathbf{1 5}$ & $\mathbf{4 3}$ & $\mathbf{2 0}$ & $\mathbf{5 7}$ & $\mathbf{3 5}$ & $\mathbf{1 0 0}$ \\
\hline \multicolumn{7}{c}{ Nilai $\mathbf{p = 0 , 0 0 6}$} \\
\hline
\end{tabular}

(Sumber : Data Primer 2020)

Dari tabel diatas dapat dilihat bahwa dari 35 responden yang menggunakan Pengetahuan Baik sebanyak 16 responden (46\%) terdiri dari Sikap Positif 12 (34\%) dan Negatif $4(11 \%)$, Pengetahuan Cukup sebanyak 13 responden (37\%) terdiri dari Sikap Positif 8 (23\%) dan Negatif 5 (14\%), Pengetahuan Kurang sebanyak 6 responden (17\%) terdiri dari Sikap Positif 0 (0\%) dan Sikap Negatif 6 (17\%)

\section{PEMBAHASAN}

Penelitian yang dilakukan peneliti di Wilayah Puskesmas Tambaruntung kepada 35 responden, menyatakan bahwa Pengetahuan Ibu Baik sebanyak 16 responden (46\%), Pengetahuan Ibu Cukup 13 responden (37\%), dan Pengetahuan Ibu Kurang 6 Responden (17\%). Sejalan dengan penelitian Atak, 
et.al (2010), mengenai faktor penyebab cedera yang tidak disengaja salah satunya tingkat pendidikan ibu. Semakin tinggi tingkat pendidikan, maka ibu dapat dengan mudah mengenali risiko-risiko cedera anak usia toddler. Sejalan dengan penelitian Indarwati (2011) tentang pengetahuan dan sikap orangtua terhadap praktik pencegahan cedera didapatkan hasil sebagaian besar responden memiliki pengetahuan yang rendah dan menunjukan terdapat hubungan antara pengetahuan orangtua dengan praktik pencegahan cedera.

Penelitian Fitri Budi Astuti (2008) menyatakan bahwa pupaya orang tua untuk mencegah cedera perlu ditingkatkan agar angka kejadian cedera menurun. Orang tua perlu mencari informasi kesehatan secara aktif untuk meningkatkan pengetahuan dan sikap orang tua. Hasil penelitian ini sejalan dengan konsep pengetahuan dari Notoatmodjo (2003), pengetahuan adalah hasil dari "tahu" dan terjadi setelah melakukan penginderaan terhadap objek tertentu. Ibu dengan tingkat pendidikan dan pengetahuan yang tinggi cenderumg lebih peduli dengan perkembangan pada anaknya, oleh karena itu aspek pengetahuan menjadi fokus utama untuk mencegah cedera pada anak. Penelitian Mubarok (2007), menyebutkan terdapat banyak faktor yang dapat mempengaruhi tingkat pengetahuan, yaitu pendidikan formal, pekerjaan, usia, minat, pengalaman hidup, kebudayaan lingkungan di sekitar serta informasi kesehatan yang didapatkan.

Berdasarkan penelitian kepada 35 responden didapatkan hasil ibu yang memiliki sikap Positif 20 (57\%) dan Negatif 15 (43\%). Hasil ini didukung oleh penelitian Kuschithawati (2007) tentang faktor risiko cedera pada anak, disebutkan bahwa setelah faktor lingkungan yang terlihat tidak aman, terdapat faktor yang paling berpengaruh dan risiko tinggi terjadinya cedera yaitu tindakan pengawasan pada anak. Kondisi tersebut sejalan dengan beberapa konsep tentang cara pencegahan cedera, menurut pendapat Wong (2008) bahwa memahami toddler merupakan dasar untuk keberhasilan mangasuh anak, Pencegahan lebih baik dari pengobatan.

Berdasarkan hasil uji statisika spearman didapatkan nilai $\mathrm{p}=0,003>(\alpha=0,05)$, yang dapat disimpulkan bahwa hipotesis penelitian diterima ( Ho di tolak ), Menyatakan ada hubungan yang bermakna antara pengetahuan dan sikap ibu mengenai pencegahan cedera dengan kejadian cedera terhadap anak usia toodler (1-3 tahun) di wilayah Puskesmas Tambaruntung Kabupaten Tapin pada Tahun 2020. Di mana Pengetahuan Ibu Baik sebanyak 16 responden (46\%), Cukup sebanyak 13 Responden (37\%), Kurang 6 Responden (17\%). Sedangkan Sikap Ibu tentang pencegahan Cedera Ibu yang memiliki Sikap Positif sebanyak 20 responden (57\%), Sikap Negatif sebanyak 15 responden (43\%).
Data tersebut menunjukan pengetahuan dan sikap yang diterapkan ibu dalam mengasuh anak-anak mereka, orang menganggap pengetahuan seperti itulah yang terbaik untuk diterapkan untuk anaknya. Kerena pengetahuan mempengaruhi pertumbuhan, 8 rembangan dan salah satunya Sikap terhadap upaya cegahan cedera pada anak usia toodler (1-3 tahun). snap ibu telah memiliki pengetahuan yang baik dalam pencegahan cedera pada anak toodler, seharusnya dapat mempraktikannya di kehidupan sehari-hari. Ibu juga dapat menunjukan sikap positif dalam pelaksanaan pencegahan cedera pada anak toodler.

Penelitian yang dilakukan kusbiantoro (2014) dari 44 responden $(15,91 \%)$ memiliki pengetahuan yang baik, hampir seluruhnya $(68,18 \%)$ orang tua memiliki pengetahuan cukup dan sebanyak 7 responden $(15,9 \%)$ pengetahuan kurang mengenai pencegahan cedera pada anak toodler. Pada aspek sikap orang tua hampir seluruhnya sebanyak 35 responden $(79 \%)$ ornag tua memiliki sifat positif sedangkan 9 responden $(20,4 \%)$ memiliki sifat negatif tentang pencegahan cedera pada anak toodler. Berdasarkan penelitian Manik (2017), hampir seluruh orang tua $(67,7 \%)$ memiliki pengetahuan yang baik, dan sisanya memiliki pengetahuan yang cukup dan kurang terhadap pencegahan cedera pada anak. Sedangkan untuk sikap dalam pencegahan cedera pada anak usia toodler seluruh orang tua (100\%) memiliki sifat positif.

\section{KESIMPULAN}

1. Pengetahuan ibu tentang pencegahan cedera yang digunakan ibu di wilayah Puskesmas Tambaruntung Kabupaten Tapin adalah baik sebanyak 16 responden (46\%) .

2. Sikap ibu tentang pencegahan cedera yang terbanyak adalah positif sebanyak 20 responden $(57 \%)$.

3. Ada hubungan yang bermakna antara antara hubungan pengetahuan dan sikap ibu tentang pencegahan cedera dengan kejadian cedera di wilayah Puskesmas Tambaruntung Kabupaten Tapin tahun 2020

\section{SARAN}

Hasil penelitian diharapkan dapat meningkatkan kualitas dan mutu dalam memberikan pelayanan kesehatan melalui upaya tentang mengadakan penyuluhan kesehatan khususnya tentang pengetahuan dan cara pencegahan bahaya cedera dan ibu diberikan pendidikan kesehatan tentang pentingnya pencegahan cedera untuk anak usia toddler (1-3 tahun) di wilayah Puskesmas Tambaruntung Kabupaten Tapin. Penelitian lebih lanjut, perlu adanya intervensi keperawatan yang komprehensif untuk menunjang pengetahuan dan sikap orangtua agar mampu 
melakukan pencegahan cedera pada anak secara mandiri.

\section{DARTAR PUSTAKA}

Adriana, D. (2011). Tumbuh Kembang \& Terapi Bermain Pada Anak. Jakarta : Salemba Medika.

Arikunto, Suharsimi. (2013). Prosedur Penelitian: Suatu Pendekatan Praktik. Jakarta : Rineka Cipta.

Budiman \& Riyanto A. (2013). Kapita Selekta Kuisioner Pengetahuan dan Sikap Penelitian Kesehatan. Jakarta : Salemba Medika.

Dewi.(2011). Teori \& Pengukuran Pengetahuan, Sikap, dan Perilaku Manusia. Yogyakarta : Nuha medika

Edelman \& Mandle. (2009). Healt Promotion Throughout The Life span 6th Edition.St. louis. Missouri : Mosby

Gary Growth. (2009). Handbook Of Psyhologocal assesment. Yogyakarta : Pustaka Pelajar.

Hastono, SP. (2006). Basic Data Analysis For Health research Training. Annalisa Data Kesehatan. Fakultas Kesehatan Masyarakat Universitas Indonesia : Jakarta.

Hidayat,A. (2009). Metode Penelitian Keperawatan dan Teknik. Analisa Data. Jakarta: salemba Medika.

Kusbiantoro, D.(2014). Perilaku Pijat Bayi Berhubungan Dengan Pengetahuan dan Dukungan Keluarga. Jurnal Surya. Volume 03, No 19.

Kuschitawati, S., Magetsari, R., Nawi. (2007). Faktor Risiko Terjadi Cedera Pada Anak Usia Toddler. Jurnal Berita Kedokteran Masyarakat.

Kyle \& Carman. (2017). Buku Ajar Keperawatan Pediatri Edisi 2. Diterjemahkan Oleh Devi Yulianti dan Dwi Widiarti. Jakarta : EGC.

Notoatmojo,S.(2011). Metodologi Penelitian Kesehatan. Jakarta : Rineka Cipta.

Nursalam, (2011). Konsep dan Penerapan Metodologi Penelitian Ilmu Keperawatan. Jakarta : Salemba Medika.

Nursalam. (2014). Manajemen Keperawatan Aplikasi dalam Praktik Keperawatan Profesional Edisi 4. Jakarta : Salemba Medika.

Papalia, E.D. dan Feldman, R.T. (2011). Meyelami Perkembangan Manusia; Experience Hman Development. Jakarta : Salemba Humanika.

Sugiono. (2011). Metode Penelitian Kuantitatif, Kualitatif dan R\&D. Alfabeta : Bandung

Wong,D.L. (2009). Buku Ajar Keperawatan Pediatric. Jakarta: EGC. 